\title{
Árboles del Valle Central de Costa Rica: reproducción del gravilia (Grevillea robusta L.)
}

\section{Trees of the Central Valley of Costa Rica: reproduction of gravilia (Grevillea robusta L.)}

\author{
Freddy Rojas-Rodríguez • Gustavo Torres-Córdoba²
}

\begin{abstract}
The following issue presents a brief description about the "Gravilia" (Grevillea robusta L.) tree , including information about its phenology which directly relates to fruit recollection, seed treatment, nursery, and germination processes.
\end{abstract}

Keywords: Fenología, manejo de semillas, viverización, germinación, árboles.

\section{Resumen}

Se presenta una breve descripción del árbol "Gravilia" (Grevilla robusta L.), información sobre fenología como base para la recolección de frutos, el manejo de las semillas, la viverización y el proceso de germinación.

Palabras clave: Phenology, seeds treatments, management at nursery, germination. 


\section{Taxonomía}

Nombre científico: Grevilla robusta L.

Nombre común: Grevilia, gravilia, roble de seda, roble australiano.

Familia: Proteaceae.

Origen: Exótica.

Distribución en el mundo: Nativa de Australia.

Distribución en Costa Rica: Introducido al Valle Central de Costa Rica como árbol asociado a cafetales.

\section{Descripción}

Árbol grande, semicaducifolio, de copa piramidal con ramas gruesas, quebradizas, muy susceptibles al viento y con marcada tendencia a la bifurcación.

Su fuste es recto con mucho ramaje. La corteza gris clara es gruesa con muchos surcos profundos, interiormente fibrosa, amarga y blanquecina.

La sustancia que exuda del tronco se usaba como goma, sustituta de la goma arábiga [1]. El árbol desarrolla un sistema radical profundo. Las hojas son parcialmente bipinnadas, alternas, con hojuelas divididas y mucho más claras y sedosas en el envés. El haz es liso de color verde oscuro y el envés es ceniciento, sedoso, con apariencia de helecho. Su tamaño oscila de 15 a $30 \mathrm{~cm}$ de largo con 11 a 21 pares de foliolos.

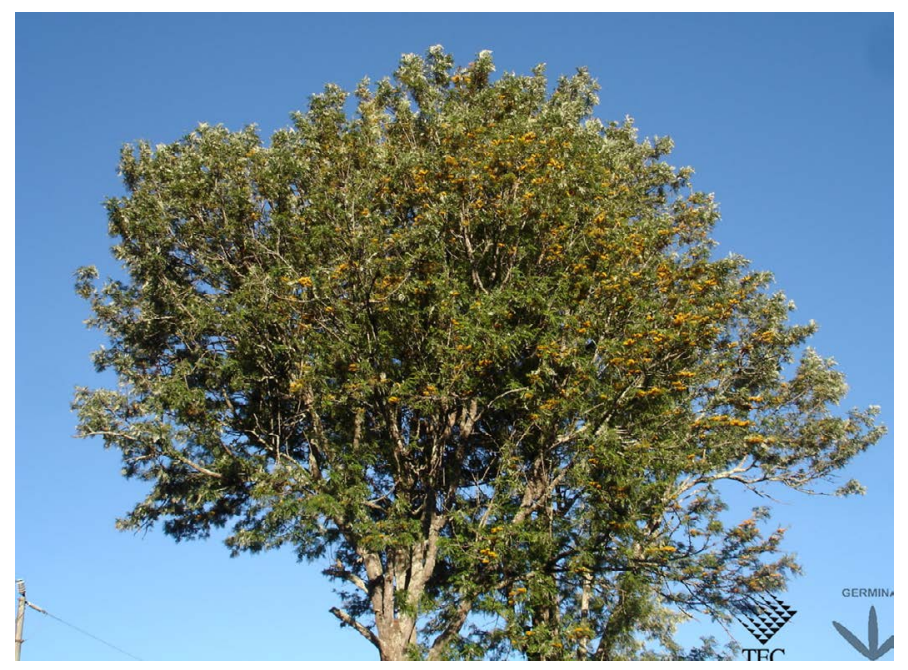

Figura 1. Perfile de Gravilia

Figure 1. Profile of "Gravilia" tree.
Presenta inflorescencias terminales con muchas flores, en forma de cepillo de color amarillo, con sépalos de color anaranjado.

El fruto es seco, dehiscente, tipo folículo, de $2 \mathrm{~cm}$ de largo, típicamente los frutos abiertos y de coloración muy oscura permanecen por mucho tiempo adheridos a las ramas.

Las semillas son comprimidas, ovoides, de 8 a $10 \mathrm{~mm}$ de largo, provistas de una ala marginal, corta, opaca, membranácea y persistente [2].

Su madera tiene un duramen que se asemeja al del roble, con bonita veta, fuerte, durable y excelente para ebanistería. Esta es resistente, elástica y moderadamente densa (peso específico 0,57). En varios países se considera que esta tiene potencial económico y para exportación. [3]

\section{Dendrofenocronograma}

En el Cuadro 1 se presenta a continuación información fenológica.

\section{Manejo de semilla y viverización}

Los frutos tipo folículo de gravilia se recolectan en los meses de febrero, marzo y abril en el Valle Central de Costa Rica. La madurez de sus frutos se reconoce por su color oscuro, dehiscencia y dispersión anemócora (por viento). La recolección preferiblemente debe hacerse con mantas o bien mediante el uso de cuerdas [2].

El procesamiento de los frutos consiste en dejarlos al sol hasta que habran. Las semillas se siembran por el método del voleo en un sustrato a base de tierra más arena. Éstas se deben cubrir apenas superficialmente, siendo que la germinación se experimenta entre 12-

Cuadro 1. Dendrofenocronograma del Gravilia, en el Valle Central, Costa Rica.

Table 1. Tree phenology through time in "Gravilia", Central Valley, Costa Rica.

\begin{tabular}{|l|l|l|l|l|l|l|l|l|l|l|l|l|}
\hline & & \multicolumn{10}{c|}{ Características } & \multicolumn{10}{c|}{} & E & F & M & A & M & J & J & A & S & O & N & D \\
\hline Hojas & & & & & & & & & & & & \\
Flores & & & & & & & & & & & & \\
Frutos verdes & & & & & & & & & & & & \\
Frutos maduros & & & & & & & & & & & & \\
\hline
\end{tabular}




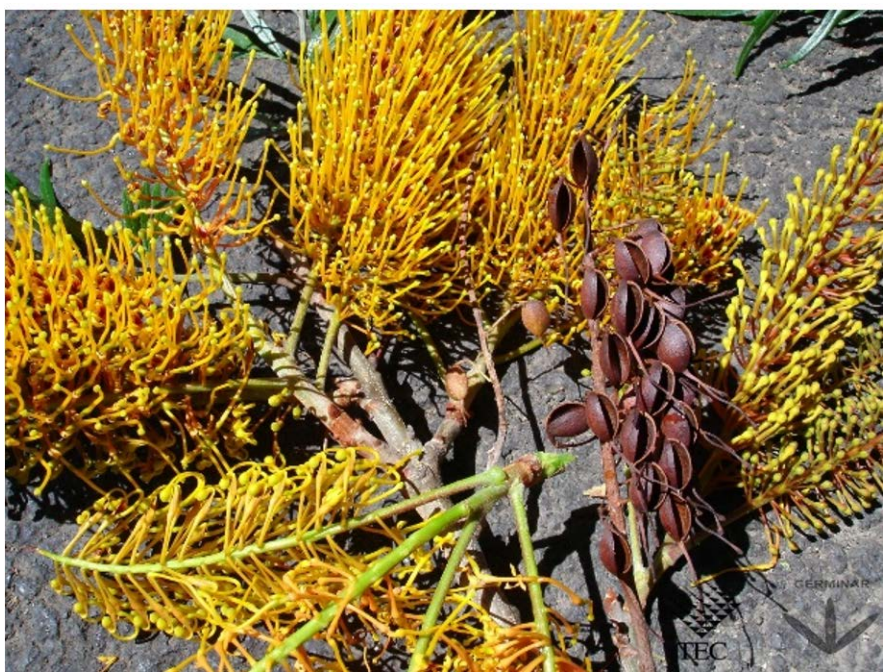

Figura 2. Flor de Gravilia.

Figure 2. Flower of "Guavilia" tree.

25 días después de la siembra. Su porcentaje de germinación, dependiendo de la calidad de la semilla, varía de un $60-84 \%$ y se puede llegar a obtener un total de 89485 semillas por kilo [2].

Las plántulas se encuentran listas para su repique o trasplante, bajo el sistema de producción en bolsa plástica o bien por estaca, dos semanas posteriores a la germinación. En cuanto al mantenimiento, no es recomendable aplicar sombra por un periodo no mayor a los 8 días, se recomienda aplicar fertilización química u orgánica en caso necesario [2].

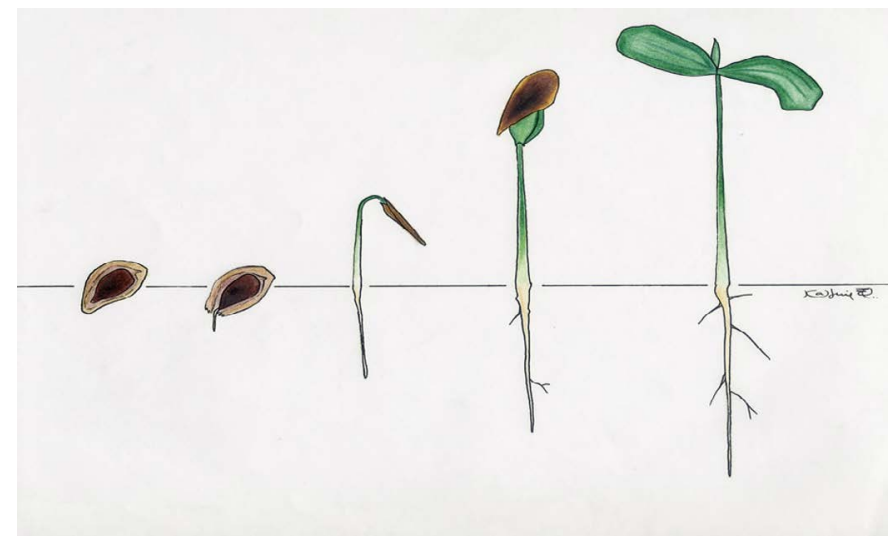

Figure 3. Proceso de germinación del Gravilia.

Figure 3. Seed germination of "Gravilia.

\section{Proceso de germinación}

El tipo de germinación del guaitil es epígea, según la figura 3.

\section{Referencias}

[1] León, J. y Poveda, L. (2000). Los nombres comunes de las plantas en Costa Rica. (Ed.) Pablo Sanchez. Editorial Guayacán: San José, Costa Rica

[2] Torres, C., Carvajal, D., Rojas, F. y Arguedas M. (2011). Reproducción de especies arbóreas y arbustivas de la región central de Costa Rica (Germinar 2.0). Cartago, Costa Rica: Instituto Tecnológico de Costa Rica. Recuperado de: https://www.tec.ac.cr/sites/default/files/media/swf/ Germinar_2/Germinar-2.swf

[3] CATIE. 1984. Especies para leña: Arbustos y árboles para la producción de energía. Proyecto Leña y Fuentes. CATIE, National Academy of Science. Talleres gráficos Trejos Hnos. 